\title{
Neurographic assessment of intramedullary motoneurone lesions in cervical spinal cord injury: consequences for hand function
}

\author{
Armin Curt and Volker Dietz \\ Swiss Paraplegic Centre, University Hospital Balgrist, Forchstrasse 340, CH - 8008 Zürich, Switzerland
}

\begin{abstract}
Examination of hand function and neurography of the median- and ulnar nerves was performed in 15 patients with acute and 26 patients with chronic tetraplegia due to cervical spinal cord injury (SCI). $30 \%$ of patients showed a mild and $20 \%$ a severe axonal lesion of motor fibres of both nerves. The latter is caused by intramedullary damage of ventral horn cells and anterior nerve roots as neurographic examination of sensory nerve fibres was normal in these patients. The most frequent and severe nerve lesion was present in those with lower cervical spinal cord injuries (C6/7-Th1) where the median and ulnar nerves originate. In the latter patients the development of active hand function, which enables the patient to perform active grasping movements, was closely related to the result of neurography, already early after trauma. The results of median and ulnar neurography in tetraplegia due to cervical SCI allow to differentiate between intramedullary damage of motoneurones and the anterior nerve roots (peripheral nervous system) or the pyramidal tract fibres (central nervous system) within the spinal cord responsible for the paresis of the intrinsic hand muscles. Neurography is of prognostic value in cervical SCI to predict the outcome of hand function and therefore influences the appropriate occupational therapy and the program and aims of rehabilitation.
\end{abstract}

Keywords: cervical spinal cord injury; tetraplegia; neurography; hand function

\section{Introduction}

Approximately $40-50 \%$ of patients with a traumatic spinal cord injury (SCI) suffer a cervical trauma with resulting tetraplegia. ${ }^{1-3}$ The independence of patients with tetraplegia in the activities of daily living and self care depends to a large extent on the ability to use the hands. ${ }^{4}$ In these patients it is advantageous to obtain as early as possible information regarding the neurological impairment of sensory and motor functions thereby allowing an early prognosis about the outcome of hand function. ${ }^{5}$ The occupational therapy of the impaired hand function in patients with tetraplegia starts in the intensive care unit after the trauma. $^{6-8}$ The approach depends largely on the degree of impairment of motor and sensory hand function and the expected functional disability. ${ }^{9}$ In particular, it is important to know whether a spastic or flaccid paresis of the intrinsic hand muscles will develop.

The aim of this study was: Firstly, to determine the extent and distribution of motor nerve lesions by neurography in traumatic cervical spinal cord injury (SCI). By the neurographic technique it is possible to differentiate between an intramedullary motor nerve lesion due to damage of ventral horn cells and anterior nerve roots within the spinal cord from other

Correspondence: Dr. A. Curt

Revised, received 19 September 1995 peripheral nerve lesions. Secondly, to correlate the neurographic results with the degree of hand function in order to evaluate, if neurography in acute cervical SCI is of prognostic value to predict the outcome of hand function.

\section{Methods}

General procedures and patients

Motor and sensory compound action potentials (MCAP/SCAP) and nerve conduction velocity (NCV) of the median and ulnar nerves were investigated in patients with acute and chronic tetraplegia due to traumatic injury of the cervical spinal cord (SCI). By normal sensory neurography peripheral nerve lesions due to polyneuropathy (eg diabetes mellitus, alcoholism) or those after polyneuritis and local nerve entrapments usually can be excluded. In this way 41 patients with SCI between $\mathrm{C} 4$ and $\mathrm{T} 1$ without indication of peripheral nerve lesions were selected (Figure 1). The level of structural injury of the spine was defined by radiographic examinations (X-ray, CT and MRI) demonstrating either a vertebral body fracture (eg. C4, C5) or a fracture with luxation (eg. $\mathrm{C} 5 / \mathrm{C} 6, \mathrm{C} 6 / \mathrm{C} 7)$. The results of the NCV study and clinical examinations of hand function will be related to the level of structural injury. In patients with acute cervical SCI and tetraplegia $(n=15$; two female, 13 
male; mean age 40 years, range 17-76 years) the examinations were performed as early as possible after admission to the hospital (usually within 1 to 2 weeks after trauma) and subsequently monthly for the next 3 months. Patients with an interval of at least 6 months after trauma in a stabilized clinical and neurological condition were placed in the chronic tetraplegic group $(n=26$, seven female, 19 male; mean 36 month after SCI, range 6-168 month; mean age 39 years, range $20-72$ years). In the group with acute tetraplegia eight of the $15(46 \%)$ and with chronic SCI 16 of the 26 $(61.5 \%)$ patients were not able to walk during the observation period.

In a group of 10 healthy subjects (five females, five males) with mean age of 29 years (range $24-38$ years) the normative data of the compound action potentials and conduction velocities of median and ulnar nerves were determined under the same condition as applied to the patient groups.

\section{Clinical examination}

Clinical examination of hand function was directed to evaluate the following points: (1) Is the patient able to use the intrinsic hand muscles voluntarily and to perform any active hand-grip. This hand function was called 'active-hand' (the patient was at least able to use two kinds of hand-grips; the pulp pinch and the lateral pinch). Patients with 'inactive-hands' were not able to perform such grips. (2) The muscle tone (spastic vs flaccid) and stretch reflexes of the intrinsic hand muscles.

\section{Recording methods}

An 'amplaid EMG equipment' was used to perform the neurographic examinations (room temperature between $21^{\circ}$ and $24^{\circ} \mathrm{C}$ ). Rectangular wave stimuli of $0.1 \mathrm{msec}$ duration were applied with supramaximal stimulus intensity to the median and ulnar nerves distally at the wrist and proximally at the elbow. Bandpass was set at $10-2500 \mathrm{~Hz}$ for motor nerves and $30-2500 \mathrm{~Hz}$ for sensory nerves. The motor nerve potentials were recorded using surface electrodes (Dantec Silver Chlor Disc Electrode) over the $\mathrm{m}$. abductor digiti minimi (ADM) and the m. abductor pollicis brevis (APB). The

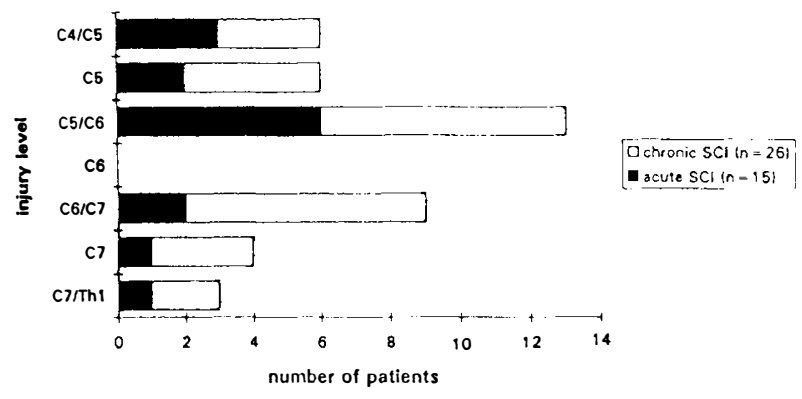

Figure 1 Distribution of the injury level in the two patient groups with acute and chronic tetraplegia due to cervical SCI sensory nerve potentials were recorded using ring electrodes from digits II and $\mathrm{V}$ by antidromic stimulation of median and ulnar nerves, respectively. Both motor and sensory neurography was performed during the same examination.

The results of the motor amplitudes of the compound action potentials (MCAP) (baseline to peak) and nerve conduction velocities (NCV) of both nerves were graded to one of four types (Table 1). Type 1: no MCAP could be recorded; type 2: pathological MCAP and NCV; type 3: normal NCV but pathological reduction of MCAP; type 4: normal amplitude of MCAP and normal NCV. This grading system allows us to differentiate disturbances of nerve function to mild axonal neuropathy (type 3), severe type of axonal neuropathy (type 2) or a complete Wallerian degeneration of the peripheral nerves with no elicitable potentials (type 1).

The grading of the neurographic results into four types of nerve lesions in the patients were related to the limits published in the literature..$^{10-12}$ In order to clearly distinguish pathological results in neurography, the limit for pathological reduction of the MCAP was defined as being less than $4 \mathrm{mV}$ for the median and $4.6 \mathrm{mV}$ for the ulnar nerve. Pathological slowing of the MNCV was determined as less than $49 \mathrm{~m} / \mathrm{s}$ for the median and $47 \mathrm{~m} / \mathrm{s}$ for the ulnar nerves. Pathological limits for the sensory results were defined to $53 \mathrm{~m} / \mathrm{s}$ for the SNCV of both nerves and reduction of SCAP of the median nerve to $20 \mu \mathrm{V}$ and for the ulnar nerve to $12.5 \mu \mathrm{V}$.

\section{Results}

\section{Healthy subjects}

The normative data studied in our group of 10 healthy subjects (Table 2A) were comparable with the data published in the literature. ${ }^{10-12}$ All subjects showed results which were within the type 4 group.

Table 1 Grading of the results of motor nerve neurography into four types according to changes in compound action potential (CAP) and the nerve conduction velocity (NCV)

\begin{tabular}{|c|c|}
\hline $\begin{array}{l}\text { Type of nerve } \\
\text { lesion }\end{array}$ & Neurographic recording \\
\hline Type 1 & $\begin{array}{l}\text { no elicitable CAP } \\
\text { (corresponding to a complete } \\
\text { nerve degeneration) }\end{array}$ \\
\hline Type 2 & $\begin{array}{l}\text { pathological reduction of CAP and } \mathrm{NCV} \\
\text { (severe axonal nerve damage) }\end{array}$ \\
\hline Type 3 & $\begin{array}{l}\text { reduction of CAP with normal NCV } \\
\text { (axonal nerve damage) }\end{array}$ \\
\hline Type 4 & $\begin{array}{l}\text { normal CAP and NCV } \\
\text { (normal neurographic recording) }\end{array}$ \\
\hline
\end{tabular}


Patients with chronic cervical SCI

About $50 \%$ of the median and ulnar motor nerves examined neurographically in the 26 patients studied were graded as type 4 (Figure 2). In $20 \%$ of the patients no motor CAP could be elicited (type 1) or the MCAP and MNCV were pathologically deranged (type 2 ). Around $30 \%$ of the median and ulnar nerves displayed a decrease of the MCAP with normal MNCV indicating a predominantly axonal lesion of these motor nerves (type 3). As expected, no patient had demyelination of motor nerve fibres. In contrast to the motor nerve fibres, the sensory nerve fibres showed normal CAP and NCV for both (Table 2). The severe nerve lesions were not symmetrically distributed in all cases. In three patients a difference in the degree of median and ulnar nerve lesions was observed between the left and the right hand (nerve lesion type 1 and 2 on the one side $v s$ type 3 on the opposite side).

The neurographic results were related to the level of the cervical SCI. Thus it could be demonstrated, that nerve lesions of both nerves corresponding to type 3 were present in injuries along the whole cervical spine, while the severe lesions of the motor nerve fibres (type 1 and type 2) were only associated with injuries at levels C6/7-T1 (Tables 3 and 4). In contrast to the healthy subjects there was a significant reduction of the mean MCAP and MNCV of median and ulnar motor nerve fibres in the patients with chronic cervical SCI with an injury level at C6/C7-T1 (level of significance 95-99\%; Table 2). There was however, no significant difference in the mean values of the sensory potentials (SCAP/SNCV) between the patients and healthy subjects (level of significance $<90 \%$ ).

\section{Patients with acute cervical SCI}

In the 15 patients with an acute cervical SCI the course of the neurographic recordings was followed over time. In 12 out of the 15 patients the first examination was done within the first two weeks after trauma. The distribution of the different types of nerve lesions was comparable to those of the chronic SCI group. The extent of the nerve lesions (type 1-4) was already present upon the initial examination and did not change significantly during further examinations. In 5 patients ${ }^{5}$ also needle electromyography of intrinsic hand muscles was also performed 1 month after trauma. In all patients with a pathologically reduced MCAP, signs of denervation were present. Although a slight increase of amplitude of the mean MCAPs was observed in patients with spastic and flaccid paresis of the hand, the mean MCAP of the median and ulnar nerves remained pathologically reduced over the observation period. The mean MCAP of the median nerve increased from initially $2.78 \pm 1.4 \mathrm{mV}$ to $3.66 \pm$ $2.5 \mathrm{mV}$ after 3 months (normal value $8.2 \pm 2.4 \mathrm{mV}$ ). The mean MCAP of the ulnar nerve increased from $3.02 \pm 1.9 \mathrm{mV}$ to $3.37 \pm 2.6 \mathrm{mV}$ (normal value $7.4 \pm 2.1 \mathrm{mV}$ ). However, this increment in both nerves was not statistically significant (student's $t$-test, level of significance $<90 \%$ ). After a period of 3 months the mean MCAP amplitude of both nerves reached a similar level as that obtained in the chronic SCI group (mean median nerve MCAP amplitude was $4.2 \pm 2.9 \mathrm{mV}$; mean ulnar nerve MCAP amplitude was $3.7 \pm 2.4 \mathrm{mV})$.

Also the motor nerve conduction velocities (MNCV) of both nerves remained stable in the examinations during the first 3 months after trauma. The mean MNCV of the median nerve was initially

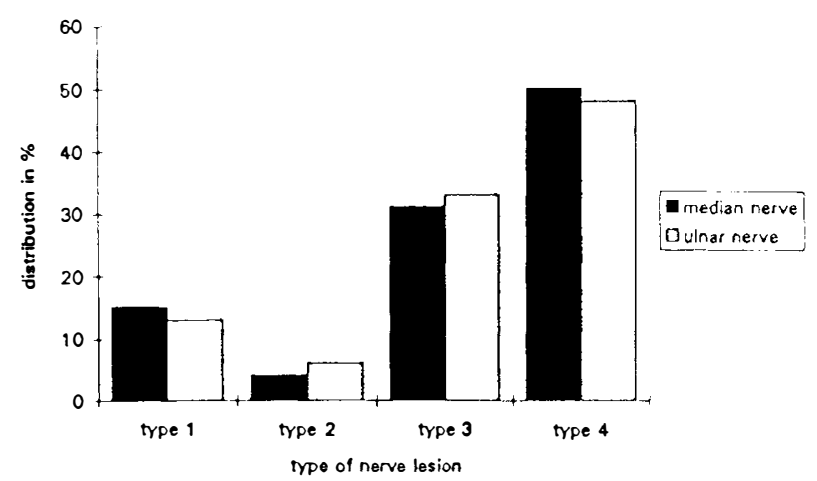

Figure 2 Neurographic grading of median and ulnar nerve lesion in patients with chronic cervical SCI into four types $(n=26)$

Table 2 Mean data of the neurographic recordings in control subjects $(\mathbf{A})$ and patients with chronic SCI $(\mathbf{B}+\mathbf{C})$.

\begin{tabular}{|c|c|c|c|c|c|c|c|c|c|}
\hline $\begin{array}{l}\text { Result of } \\
\text { neurography }\end{array}$ & & $\begin{array}{c}\text { Median } \\
M C A P \mathrm{mV}\end{array}$ & $\begin{array}{c}M N C V \\
\mathrm{~m} / \mathrm{s}\end{array}$ & $\begin{array}{c}S C A P \\
\mu \mathrm{V}\end{array}$ & $\begin{array}{c}S N C V \\
\mathrm{~m} / \mathrm{s}\end{array}$ & $\begin{array}{c}\text { Ulnar } \\
M C A P \mathrm{mV}\end{array}$ & $\begin{array}{c}M N C V \\
\mathrm{~m} / \mathrm{s}\end{array}$ & $\begin{array}{c}S C A P \\
\mu \mathrm{V}\end{array}$ & $\begin{array}{c}S N C V \\
\mathrm{~m} / \mathrm{s}\end{array}$ \\
\hline $\begin{array}{l}\text { Control } \\
\text { group } \\
(n=20)\end{array}$ & $\mathbf{A}$ & $8.2 \pm 2.4$ & $58.9 \pm 3.3$ & $34.2 \pm 10$ & $62.6 \pm 4.7$ & $7.4 \pm 2.1$ & $57.9 \pm 3.7$ & $20.7 \pm 5.5$ & $61.2 \pm 4.1$ \\
\hline $\begin{array}{l}\mathrm{C} 4 / 5-\mathrm{C} 6 \\
(n=24)\end{array}$ & B & $5.6 \pm 2.6$ & $55.4 \pm 6.2$ & $33.6 \pm 17.1$ & $61.0 \pm 7.9$ & $4.1 \pm 1.1$ & $54.2 \pm 8.4$ & $20.5 \pm 17.8$ & $57.5 \pm 9.7$ \\
\hline $\begin{array}{l}\text { C6/7-T } 1 \\
(n=22)\end{array}$ & C & $2.7 \pm 2.6^{* *}$ & $35.4 \pm 25.2^{* *}$ & $26.3 \pm 17.2$ & $59.2 \pm 5.3$ & $3.2 \pm 3.2^{*}$ & $39.2 \pm 25.3^{*}$ & $21.3 \pm 14.6$ & $56.7 \pm 8.5$ \\
\hline
\end{tabular}

The values of control group A and patient group C (lower cervical lesions) are significantly different $(*$ level of significance $95<99 \%,{ }^{* *}$ level of significance $99-99.9 \% ; n=$ number of nerves examined) 
$51.8 \pm 8.8 \mathrm{~m} / \mathrm{s}$ and decreased to $47.2 \pm 15.5 \mathrm{~m} / \mathrm{s}$ whereas the mean MNCV of the ulnar nerve decreased from $55.3 \pm 3.7 \mathrm{~m} / \mathrm{s}$ to $50.8 \pm 5.7 \mathrm{~m} / \mathrm{s}$ after 3 months. The slowing in the conduction velocities of both nerves was not significant (level of significance $<90 \%$ ). Again the results obtained 3 months after trauma were similar to the values recorded from the chronic SCI patients (mean median nerve MNCV was $45.8 \pm 20.4 \mathrm{~m} / \mathrm{s} ;$ mean ulnar nerve $\mathrm{MNCV}$ was $47.3 \pm 19.5 \mathrm{~m} / \mathrm{s})$.
Neurography and clinical symptoms

In chronic SCI patients with a severe nerve lesion (type 1 and 2) the muscle tone was reduced with a flaccid paresis and absence of stretch reflexes of the intrinsic hand muscles. In acute cervical SCI with neurographical results corresponding to type 1 and 2 the development of flaccid muscle tone and reduced stretch reflexes was predicted. Patients with complete tetraplegia due to lesions of the upper cervical segments and neurographic results in both nerves of

Table 3 Correlation between the neurographic results of median motor nerve and hand function of both patient groups in respect to SCI level ( $\square=$ no active function of intrinsic hand muscles; $\boldsymbol{\square}=$ hand muscle function with active grasping)

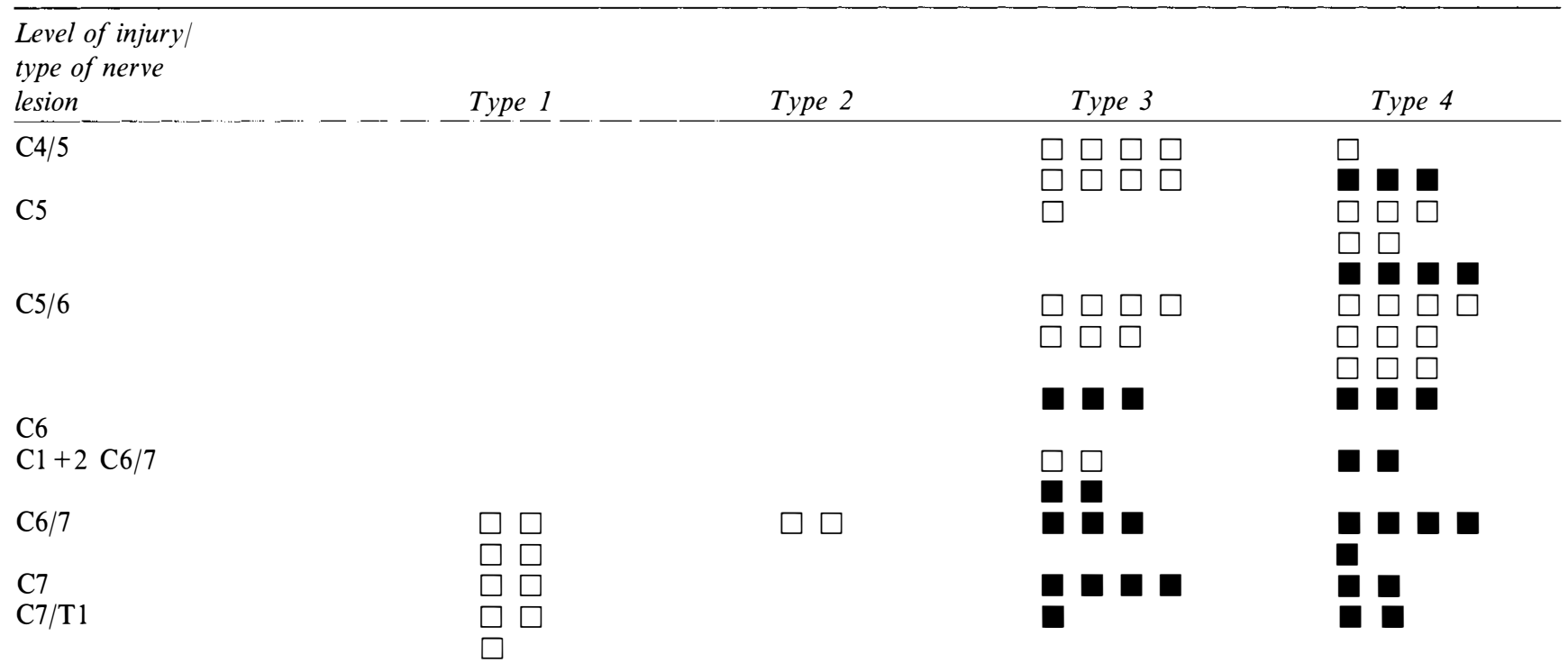

Table 4 Correlation between the neurographic results of ulnar motor nerve and hand function in both patient groups in respect to SCI level ( $\square=$ no active function of intrinsic hand muscles; $\square=$ hand muscle function with active grasping)

\begin{tabular}{|c|c|c|c|c|}
\hline $\begin{array}{l}\text { Level of injury/ } \\
\text { type of nerve } \\
\text { lesion }\end{array}$ & Type 1 & Type 2 & Type 3 & Type 4 \\
\hline $\mathrm{C} 4 / 5$ & & & $\begin{array}{l}\square \square \square \\
\square \square \square\end{array}$ & $\square \square$ \\
\hline $\mathrm{C} 5$ & & & $\square \square \square$ & $\begin{array}{l}\square \square \square \\
\square \square\end{array}$ \\
\hline $\mathrm{C} 5 / 6$ & & & $\begin{array}{l}\square \square \square \square \\
\square \square \square \square \\
\square \square \square\end{array}$ & $\begin{array}{l}\square \square \bar{\square} \\
\square \square \square \\
\square \square\end{array}$ \\
\hline $\begin{array}{l}\mathrm{C} 6 \\
\mathrm{C} 1+2 \mathrm{C} 6 / 7\end{array}$ & & $\square \square$ & 口 & \\
\hline $\mathrm{C} 6 / 7$ & $\square \square$ & & 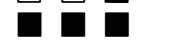 & \\
\hline $\mathrm{C} 7$ & $\square \square$ & & & \\
\hline $\mathrm{C} 7 / \mathrm{T} 1$ & $\square \square$ & $\square$ & & \\
\hline
\end{tabular}


type 3 and 4 developed a spastic hand paresis with increased muscle tone and exaggerated stretch reflexes. In patients with upper cervical SCI and incomplete tetraplegia the neurographic results were not related to the muscle tone and stretch reflex excitability.

\section{Neurography and hand function}

The hand function was differentiated into active and inactive hands, depending upon whether the patient was able to voluntarily perform active grasping movements using intrinsic hand muscles. In the chronic SCI patients, $18(35 \%)$ out of 52 hands were clinically defined to represent an active hand. In acute SCI patients, $16(53 \%)$ out of 30 hands were classified as active hands. Neurographic results in both patient groups were of different diagnostic and prognostic value with respect to hand function in lesions of upper or of lower cervical segments. There was no correlation between the neurographic results and hand function in patients with upper cervical lesion (segments C4/5-C6) in both acute and chronic patients. Furthermore, no difference could be determined between hand paresis with inactive hand function due to complete tetraplegia and active/normal hand function in incomplete tetraplegics. In contrast, in lesions of the lower segments $(\mathrm{C} 6 / 7-\mathrm{Th} 1)$ there was a strong correlation between the outcome of hand function and the neurographic results (Tables 3 and 4). In the latter patients $90 \%$ of the hands with neurographic results corresponding to type 3 and 4 developed active grasping movements of the hands (versus $35 \%$ in lesions of upper segments). All hands with median and ulnar nerve lesions corresponding to grading type 1 and 2 remained with an inactive hand function. The hands of patients with asymmetrical nerve lesions were characterized by a hand function corresponding to the remaining innervation of intrinsic hand muscles.

\section{Discussion}

In cervical spinal cord injuries central and peripheral parts of the motor system can be affected: (1) Descending motor nerve fibres of the central nervous system, ie the pyramidal tract and (2) structures within the anterior part of the spinal cord, ie motoneurones and anterior nerve roots, belonging to the peripheral nervous system. Therefore, lesions of the cervical spinal cord can produce a more spastic or flaccid paresis of the hand muscles depending on the predominantly damaged nervous structure (peripheral or central). One has to be aware that the peripheral sensory nerve fibres in contrast to the motor fibres originate in the extramedullary located dorsal ganglions. Therefore, with intramedullary damage of the spinal cord sensory fibres of the peripheral nerves, in contrast to motor nerve fibres which undergo Wallerian degeneration, are usually not or only little affected.

In patients with tetraplegia due to cervical SCI the therapy of the remaining hand function is most important to attain a maximum of self-independence. ${ }^{9,13}$ During the first few weeks after SCI, para-/tetraplegic patients display a lack of stretch reflexes and muscle tone is reduced below the level of injury due to spinal shock. ${ }^{14-16}$ Theref ore, one cannot clinically distinguish between peripherally or centrally mediated paresis by the initial neurological examination.

Alterations of the peripheral nervous system of the lower limbs in patients with traumatic SCI and in patients with non-traumatic disorders of the spinal cord by neurographic and myographic examinations were already demonstrated earlier. ${ }^{17-20}$ Hitherto there exists, however, no study of neurographic recordings of upper limbs in tetraplegia to evaluate the extent of motor nerve lesion and its potential relevance to the clinical outcome of hand function.

\section{Extent and distribution of motor nerve lesion}

In the acute and chronic patient groups, approximately $50 \%$ of patients displayed significant lesion of the median and ulnar motor nerve fibres and of these $20 \%$ suffered severe nerve lesions. Because the neurography of sensory nerve fibres was normal in these patients, the motor nerve lesion has to be due to an intramedullary lesion of the motoneurones. Therefore, this type of nerve lesion can be separated from other peripheral nerve lesions (eg plexus lesion or peripheral nerve entrapment) frequently present in wheelchair bound patients. ${ }^{21-23}$ Krasilovski (1980) described in a nerve conduction study severe upper limb nerve lesions in $17 \%$ of patients with chronic cervical SCI and attributed the nerve lesions mainly to peripheral nerve entrapments (eg ulnar - carpal channel) and to chronic affection of the ventral horn cells. ${ }^{24}$ However, in the latter study the time course of these nerve lesions was not investigated and the early development was not described.

In our patient groups, where peripheral nerve entrapments were excluded, we could demonstrate that the motor nerve lesion is already present in acute cervical SCI. It can be assumed that this damage belongs rather to local trauma of the cervical spinal cord than to reduction of supraspinal input to the ventral horn cells, because the most severe lesions of motor nerve fibres (type 1 and 2) only occurred in lower cervical SCI injuries where these nerves originate. $^{25-30}$ This suggestion also fits in with the observation that only $10 \%$ of patients with severe intramedullary motoneurone lesions regained the ability to walk, in contrast to $40 \%$ of patients with mild or no nerve lesion. Therefore, a more severe intramedullary motoneurone lesion is associated with a greater local intramedullary damage of neuronal structures with consecutive poor prognosis of upper and lower limb motor function. The distribution of nerve lesion in neurography described in our study is 
in line with earlier EMG studies, where most of the patients with cervical SCI showed signs of denervation, eg pathological spontaneous activity in the upper limb muscles at, below, and to a lesser degree, above the neurological level of spinal cord damage. ${ }^{31,32}$

Compared to the latter studies the neurographic recordings employed here allow to assess quantitatively the motor nerve lesion and to follow its time course. Additionally, neurography may help to differentiate between intramedullary and other peripheral nerve lesions. Furthermore, the neurographic recordings can indicate at an early stage the extent and severity of intramedullary motoneurone lesions, and can serve as a screening method for these lesions.

\section{Motor nerve lesion and hand function}

In patients with acute lower cervical SCI (C6/7-Th1) the MCAP amplitudes were of prognostic value to predict the outcome of hand function. Patients with a severe motor nerve lesion of median and ulnar motoneurons (type 1 and 2) developed flaccid paresis of the intrinsic hand muscles associated with muscle atrophy and a loss of stretch reflexes. These patients obtained no active hand function, ie they were not able to perform any active grasping movements by the intrinsic hand muscles. In contrast, patients with a less severe nerve lesion (type 3 and 4) developed active hand function with the ability to perform active grasping movements. As a consequence, the latter patients were more self-independent. Patients with asymmetrical motoneurone damage showed a hand function which was related to the degree of preserved nerve function.

In patients with upper cervical SCI $(\mathrm{C} 4 / 5-\mathrm{C} 6)$ no severe nerve lesion was observed. In these patients an inactive hand function due to a central hand paresis (damage of pyramidal tract) or an active hand function in incomplete cervical spinal cord injury could not be differentiated by neurography. Therefore, in these patients neurography was only of indirect value for the prognosis of hand function. These patients with an inactive hand function, in contrast to flaccid hand muscle paresis, could use to a certain extent the spastic muscle tone to acquire some hand function, ie passive grasping movements. Therefore, the development of flaccid or spastic hand muscles paresis could be predicted on the basis of combined clinical and neurographic examinations.

\section{Conclusion}

A motor nerve lesion was present in $50 \%$ of patients with tetraplegia due to cervical SCI. A severe motor nerve lesion was predominantly present in lower cervical injuries. Neurographic examination is of diagnostic value in cervical SCI, as it can predict the development of hand function and muscle tone and thus influences the selection of occupational hand therapy and the rehabilitation program.

\section{Acknowledgements}

This work was supported by the International Institute for Research in Paraplegia (P17/V Dietz) and the Swiss National Science Foundation (Grant No. 31-33567.92).

\section{References}

1 Kiwerski J, Weiss M. Neurological Improvement. In Traumatic Injuries Of Cervical Spinal Cord. Paraplegia 1981; 19: 31-37.

2 Young JS, Northrup NE. Statistical information pertaining to some of the most commonly asked questions about SCI. Phoenix, Arizona, National Spinal Cord Injury Research Center, 1979.

3 Frankel HL et al. The value of postural reduction in the initial management of closed injuries of the spine with paraplegia and tetraplegia. Paraplegia 1969; 7: 179-192.

4 Waters RL, Adkins RH, Yakura JS, Sie I. Motor and sensory recovery following incomplete tetraplegia. Arch Phys Med Rehabil 1994; 75: $306-311$.

5 Ditunno JF et al. Wrist extensor recovery in traumatic quadriplegia. Arch Phys Med Rehabil 1987; 68: 287-290.

6 Curtin M. Development of a tetraplegic hand assessment and splinting protocol. Paraplegia 1994; 32: 159- 169.

7 Krajnik SR, Bridle MJ. Hand splinting in quadriplegia: current practice. Am J Occup Ther 1992; 46: 149-156.

8 Fess EE, Phillips CA. Hand splinting: Principles and methods 2nd ed. St. Louis: Mosby, 1987.

9 Ditunno JF, Stover SL, Freed MM, Ahn JH. Motor recovery of the upper extremities in traumatic quadriplegia: a multicenter study. Arch Phys Med Rehabil 1992; 73: 431 - 436.

10 Robinson LR et al. Influences of height and gender on normal nerve conduction studies. Arch Phys Med Rehabil 1993; 74: $1134-1138$.

11 Hennessey WJ, Falco FJE, Braddom RL. Median and ulnar nerve conduction studies: normative data for young adults. Arch Phys Med Rehabil 1994; 75: 259-264.

12 Kimura J. Principles and pitfalls of nerve conduction studies. Ann Neurol 1984; 16: 415-429.

13 Lathem PA, Gregorio TL, Garber SL. Highlevel quadriplegia: An occupational therapy challenge. Am J Occup Ther 1985; 39: $705-714$

14 Hall M. New memoir on the nervous system. London: H. Bailliere, 1843.

15 Rossier AB, Fam BA, Dibenedetto M, Sarkarati M. Urodynamics in spinal shock patients. J Urol 1979; 122: $783-787$.

16 Guttman L. Spinal shock and reflex behaviour in man. Paraplegia 1970; 8: 100-110.

17 Boltshauser E, Isler W, Bucher HU, Friderich H. Permanent flaccid paraplegia in children with thoracic spinal cord injury. Paraplegia 1981; 19: 227-234.

18 Shemesh Y, Rozin R, Ohry A. Electrodiagnostic investigation of the motor neuron and spinal reflex arch (H-Reflex) in spinal cord injury. Paraplegia 1977; 15: $238-244$.

19 Blaik Z, McGarry J, Daura R. Peripheral neuropathy in spinal cord injured patients. Electromyogr Clin Neurophysiol 1989; 29: $469-472$.

20 Takebe K, Narayan MG, Kukulka C, Basmajian JV. Slowing of nerve conduction velocity in hemiplegia: possible factors. Arch Phys Med Rehabil 1975; 56: 285-289.

21 Laurence TN, Pugel AV, Teasdall RD. Peripheral nerve involvement in spinal cord injury: An electromyographic study. Arch Phys Med Rehabil 1978; 59: 309-313.

22 Stark RJ, Kennard C, Swash M. Hand wasting in spondylotic high cord compression: an electromyographic study. Ann Neurol 1980; 9: $58-62$.

23 Stefaniwsky L, Bilowit DS, Prasad SS. Reduced motor conduction velocity of the ulnar nerve in spinal cord injured patients. Paraplegia 1980; 18: $21-24$.

24 Krasilovsky G. Nerve conduction studies in patients with cervical spinal cord injuries. Arch Phys Med Rehabil 1980; 61: 204-208. 
25 Nyboer VJ, Johnson HE. Electromyographic findings in lower extremities of patients with traumatic quadriplegia. Arch Phys Med Rehabil 1971; 52: 256-259.

26 Campbell JW et al. Spontaneous electromyographic potentials in chronic spinal cord injured patients: relation to spasticity and length of nerve. Arch Phys Med Rehabil 1991; 72: $23-27$.

27 Dahlström A, Heiwall P, Bööj S, Dahllöf A. The influence of supraspinal impulse activity on the intra-axonal transport of acetycholine, choline acetyltransferase and acetylcholinesterase in rat motor neurons. Acta Physiol Scand 1978; 103: 308-319.

28 Taylor RG, Kewalramani LS, Fowler WM. Electromyographic findings in lower extremities of patients with high spinal cord injury. Arch Phys Med Rehabil 1974; 55: 16-23.

29 Benecke R, Berthold A, Conrad B. Denervation activity in the EMG of patients with upper motor neuron lesions: time course, local distribution and pathogenetic aspects. J Neurol 1983; 230: $143-151$.
30 Parry GJ. Electrodiagnostic studies in the evaluation of peripheral nerve and brachial plexus injuries. The Neurology of Trauma 1992; 4: 921 - 934.

31 Brandstater ME, Dinsdale SM. Electrophysiological studies in the assessment of spinal cord lesions. Arch Phys Med Rehabil 1976; 57: $70-74$.

32 O'Hare JM, Abbort GH. Electromyographic evidence of lower motor neuron injury in cervical spinal cord injury. Proc Annu Clin Spinal Cord Inj Conf 1967; 16: 25-27. 